\title{
Assessment of Factors that Contribute to Deforestation in Shabe Sombo Woreda, Jimma Zone, South West Ethiopia
}

Guta Waktole Waktole Weyesa ( $\sim$ waaqtoleegutaa@gmail.com )

Ethiopian Biodiversity Institute

Research

Keywords: anthropogenic factors, jimma Zone, agriculture, sombo woreda

Posted Date: January 29th, 2021

DOl: https://doi.org/10.21203/rs.3.rs-153980/v1

License: (c) (1) This work is licensed under a Creative Commons Attribution 4.0 International License.

Read Full License 


\section{Abstract}

Deforestation is the process of removing forest areas and using the land for other uses. Deforestation also has been described as the cutting down of trees without planting others in their place. The causes of deforestation are varied but may broadly be categorized into anthropogenic and natural factors. For the anthropogenic factors, increased wood fuel collection, clearing of forests for agriculture, illegal and poorly regulated timber extraction, social and environmental conflicts, increasing urbanization and industrialization. This study is aimed to assess the deforestation status and contributing factors in making Shabe Sembo woreda, Jimma Zone South West Ethiopia. The main objective of this study is to assess the factors that contribute to deforestation in Shabe sombo woreda, jimma Zone, South West Ethiopia. The study has been conducted in Shabe Sombo woreda located in Jimma Zone, Oromia regional state. A cross sectional study design has been employed. The source of population was all households found in Shabe sombo Woreda. The sample size of this study was 100 householders from 1200 total households. Data were collected by using open and close ended questionnaires for gathering important information used for this study. About 52(54.167\%) of the respondents reported that the most factor contributing to deforestation in Shabe Sombo was expansion of agricultural land. Whereas About $28(29.167 \%)$ of the respondents reported as cutting trees for fire wood is one factor contributing to deforestation in shabe Sombo woreda, Jimma zone, Southwest Ethiopia.

\section{Back Ground Of The Study}

\subsection{Introduction}

Deforestation is the process of removing forest areas and using the land for other uses. These other uses can include settlements, industrialization or agriculture. Deforestation also has been described as the cutting down of trees without planting others in their place.

It is hard to think that there was a time when $90 \%$ of the earth was covered by trees. Even though people are becoming more and more aware of the serious effects deforestation is having on the earth, the number of forests being destroyed is still very high (Spracklen, 2012).

The main question about the One of the consequences of deforestation is that the carbon originally held in forests is released to the atmosphere, either immediately if the trees are burned, or more slowly as unburned organic matter decays. Cultivation also oxidizes $25-30 \%$ of the organic matter in the upper meter of soil and releases that to the atmosphere. Reforestation reverses these fluxes of carbon. While forests are re growing, they withdraw carbon from the atmosphere and accumulate it again in trees and soil. Current estimates of carbon emissions from tropical deforestation The emissions of carbon from tropical deforestation are determined by two factors: rates of land-use change (including harvest of wood and other forms of management) and per hectare changes in carbon stocks following deforestation (or harvest) (Betts, 2004). 
The causes of deforestation are varied but may broadly be categorized into anthropogenic and natural factors. For the anthropogenic factors, increased wood fuel collection, clearing of forests for agriculture, illegal and poorly regulated timber extraction, social and environmental conflicts, increasing urbanization and industrialization are the primary known causes for the loss of forests and woodlands (FAO, 2002). For the natural factors, the impacts of drought and natural forest fires have been highlighted in the cases of Australia and Ghana (FAO, 2010; Insaidooet al, 2012).

Because of the variety of ecosystems and land uses, and because annual changes require accounting for cohorts of different ages, bookkeeping models are often used to calculate the emissions and uptake of carbon over large regions By practicing deforestation the forest areas provide lumber for commercial materials, farming and grazing land for the every growing cattle population, charcoal as fuel for cooking and heating. Roads and mines are being built as well as towns and cities. Forests are becoming exhausted in developed nations and our attention is now on the tropical areas, more specifically the tropical rain forests. We are dependent on forests for our livelihood. As the forests disappear, resources are becoming scarcer. Third world or underdeveloped nations are being extorted for their forests and are given minimal return for the damage done to their own country (Spracklen, 2012).

People, especially those who live in rural areas where electricity and gas are unavailable, resort to use of firewood as a source of heat. Here, wood is cut down and burnt. Those proximate reasons are accompanied by underlying causes for deforestation. Faced by food insecurity agricultural land is just more valuable to farmers. Individual farmers do not have many other options than converting forests into agricultural land if they are exposed to severe food insecurity. Their time preference rates are low which means they prefer food today over tomorrow and they definitely cannot carry the costs of forest conservation for the larger national or global society (Gatzweiler.,et al 2007)

Historically, forests have been very important for the livelihoods of the people of Ethiopia. The Ethiopian people used trees for lumber for construction, and to fuel their cooking fires. They also made traditional medicines from trees and other forest plants. Forests were also important in Ethiopian religious beliefs; the people believed in holy spirits in the forest that they treat in the same way as human beings.. At the beginning of the twentieth century around 420,000 square kilometres (35\% of Ethiopia's land) was covered by trees but recent research indicates that forest cover is now less than $14.2 \%$ due to population growth. Despite the growing need for forested lands, lack of education among locals has led to a continuing decline of forested areas (Parry, 2003).

A plantation of trees established primarily for timber production to be forest and therefore does not classify natural forest conversion to plantation as deforestation (but still records it as a loss of natural forests). However, FAO does not consider tree plantations that provide non-timber products to be forest although they do classify rubber plantations as forest. Forest degradation occurs when the ecosystem functions of the forest are degraded but where the area remains forested rather cleared (Anon, 2010).

If the society know the impact of deforestation the do not practice the things those have negative effect on forest. Knowing the factors that contribute to deforestation are very important to protect and conserve 
biodiversity of our country. Even though some researchers have been conducted in Ethiopia regarding deforestation problems, there is no documented information in relation to the forest status of Shabe Sembo District. Therefore this study is aimed to assess the deforestation status and contributing factors in making Shabe Sembo woreda, Jimma zone, South Ethiopia.

\subsection{Statement of the Problem}

Much of the bulk of forest resources exist outside protected areas and beyond active management authorities of conservation programs and projects. Local communities, therefore, are the primary stewards of forest resources. These resources are usually characterized by the local communities' culture and management systems, where cultures are materially and spiritually built upon the physical world of the forests. Local communities' proper access to forest resources around them and respect to their traditional institutions and systems of management of these resources provides the opportunity for safeguarding the resources sustainably (Regassa, 2001).

Knowing the factors that contribute to deforestation is very important to protect and conserve biodiversity of our country. Even though some researchers did on this title before this time, it is important to know the current factors contributing to deforestation. So, the researcher was interested to do research on this title to assess the current factors contributing to deforestation in shabesombo woreda, jimma zone.

\subsection{Objective}

\subsubsection{General Objective}

To assess the factors that contribute to deforestation in Shabesombo woreda, jimma zone, Oromia.

\subsubsection{Specific Objectives}

- To assess the attitude and practices of residents towards forest conservation in the study area

- To identify the major factors contributing to deforestation in shabesombo woreda.

\subsection{Significance of the Study}

The significance of this study is for forest resources conservation to succeed and its use to be sustainable, knowing the factors contributing to deforestation and forest management practices have to be considered at all levels of conservation efforts. This research will also recommend concerned bodies for further investigation and for the increment of knowledge factors contribute to deforestation since these factors are identified by this assessment the society concerned body may give the solution for deforestation and can work on preventing those factors. 


\subsection{Scope of the study}

Households found in Shabe sombo woreda are large in number which is difficult to assess the factors contributing to deforestation in this woreda. To overcome this difficulty it is necessary to demarcate the scope of the study. Hence, the work has been delimited to be done in Shabe Sombo which domains households found in Shabe Sombo Woreda only.

\section{Literature Review}

Deforestation is the conversion of forest to an alternative permanent non-forested land use such as agriculture, grazing or urban development. Deforestation is primarily a concern for the developing countries of the tropics, as it is shrinking areas of the tropical forests (Barraclough and Ghimire, 2000) causing loss of biodiversity and enhancing the greenhouse effect.

Deforestation occurred at the rate of 9.2 million hectares per annum from 1980-1990, 16 million hectares per annum from 1990-2000 and decreased to 13 million hectares per annum from 2000-2010. The net change in forest area during the last decade was estimated at -5.2 million hectares per year, the loss area equivalent to the size of Costa Rica or $140 \mathrm{~km} 2$ of forest per day, was however lesser than that reported during 1990-2000 which was 8.3 million hectares per year equivalent to a loss of 0.20 per cent of the remaining forest area each year. The current annual net loss is 37 per cent lower than that in the 1990s and equals a loss of 0.13 per cent of the remaining forest area each year during this period (Rowe et al., 1992).

\subsection{The causes of deforestation}

\subsubsection{Direct causes}

\subsubsection{Expansion of farming land}

Shifting agriculture also called slash and burn agriculture is the clearing of forested land for raising or growing the crops until the soil is exhausted of nutrients and/or the site is overtaken by weeds and then moving on to clear more forest. It is been often reported as the main agent of deforestation. Smallholder production in deforestation and the growing number of such producers notably shifting cultivators were the main cause of deforestation. Mostly all reports indicate shifting agriculture as responsible for about one half of tropical deforestation and some put it up to two-thirds. Shifting agriculture was greatest in Asia (about $30 \%$ ) but only about $15 \%$ over the whole tropical world. It appears that the proportion of direct conversion of forest to agriculture is increasing and the proportion of shifting agriculture is decreasing with time(Ross, 1996). 
Despite the downward trend in world coffee prices, farmers are unable to receive government assistance for anything but the cultivation of coffee. Yet, an average coffee plantation remains productive for a mere 20 years, after which time the land may be planted with grass and made into pasture for livestock, but eventually must be abandoned. This process is costly, coffee markets are unstable, and the forest continues to be cleared (Gatzweileret al., 2007

\subsubsection{Forest and other plantations}

Plantations are a positive benefit and should assist in reducing the rate of deforestation. The fact that plantations remove the timber pressure on natural forests does not translate eventually into less, but rather into more deforestation. Indeed, it is feared that agricultural expansion which is the main cause of deforestation in the tropics might replace forestry in the remaining natural forests (Anon, 2005).

\subsubsection{Logging and fuel wood}

Fuelwood is not usually the major cause of deforestation in the humid tropics although it can be in some populated regions with reduced forest area such as in the Philippines, Thailand and parts of Central America. Fuelwood gathering was considered to be the main cause of deforestation and forest degradation in El Salvador (Repetto, 1990).

\subsubsection{Overgrazing}

Overgrazing is more common in drier areas of the tropics where pastures degraded by overgrazing are subject to soil erosion. Stripping trees to provide fodder for grazing animals can also be a problem in some dry areas of the tropics but is probably not a major cause of deforestation.Overgrazing are causing large areas of grasslands north of Beijing and in Inner Mongolia and Qinghai province to turn into a desert. One man who lived in a village on the eastern edge of the Qinghai-Tibet plateau that was being swallowed up by sand told the New York Times, "The pasture here used to be so green and rich. But now the grass is disappearing and the sand is coming." Huge flocks of sheep and goats strip the land of vegetation (Hays, 2008 web page).

\subsubsection{Fires}

Fires are a major tool used in clearing the forest for shifting and permanent agriculture and for developing pastures. Fire is a good servant but has a poor master. Fire used responsibly can be a valuable tool in agricultural and forest management but if abused it can be a significant cause of deforestation (Rowe et al., 1992).

\subsubsection{Mining}


Mining is very intensive and very destructive (Mather, 1991; Sands, 2005). The area of land involved is quite small and it is not seen as a major cause of primary deforestation. Mining is a lucrative activity promoting development booms which may attract population growth with consequent deforestation. Roads constructed to support the mining operations will open up the area to shifting agriculturists, permanent farmers, ranchers, land speculators and infrastructure developers. For instance the core of Brazil's Amazon development strategy were infra-structure development projects such as roads providing access to frontier regions, mining area and large hydroelectric reservoirs (Carvalho et al., 2004).

\subsubsection{Urbanization/industrialization and infra-structure}

Expanding cities and towns require land to establish the infrastructures necessary to support growing population which is done by clearing the forests. Tropical forests are a major target of infra-structure developments for oil exploitation, logging concessions or hydropower dam construction which inevitably conveys the expansion of the road network and the construction of roads in pristine areas. The construction of roads, railways, bridges, and airports opens up the land to development and brings increasing numbers of people to the forest frontier (Sands, 2005).

\subsubsection{Air pollution}

Air pollution is associated with degradation of some European and North American forests. The syndrome is called "Waldsterben" or forest death. In 1982, eight per cent of all West German trees exhibited damage that rose to about 52 per cent by 1987 (Raloff, 1989)

\subsubsection{Tourism}

National parks and sanctuaries beyond doubt protect the forests, but uncautioned and improper opening of these areas to the public for tourism is damaging. Unfortunately, the national governments of tropical and sub-tropical countries adopt tourism for easy way of making money sacrificing the stringent management strategies. Further, many companies and resorts who advertise themselves as eco-tourist establishments are in fact exploiting the forests for profit. In Cape Tribulation, Australia, for example, the rain forest is being threatened by excessive tourism (Colchester and Lohmann, 1993).

\subsection{Indirect causes}

\subsubsection{Colonialism}

Erstwhile colonies of the colonial powers like Britain, France, Spain or Portugal are now the Third World Countries or the developing nations mostly have the tropical rainforests except Australia and Hawaii were exploited for their natural resources and their indigenous people's rights destroyed by the colonial powers. 
All these countries have indigenous populations who had their own system of land management and/or ownership in place for thousands of years before the intervention of colonists from rich industrialized nations. Colonialism turned previously self-sufficient economies into zones of agriculture export production. This process continues even today in different form of exploitation and the situation is worsening (Colchester and Lohmann, 1993).

\subsubsection{The debt burden}

Pursuing the guided development agenda, the financially poorer countries are on a heavy international debt and now feeling the urgency of repaying these huge debts due to escalating interest rates. Such a situation compels these debt ridden poorer countries to Global Perspectives on Sustainable Forest Management exploit their rich natural resources including their forests partly to earn foreign exchange for servicing their debts (Colchester and Lohmann, 1993).

\subsubsection{Overpopulation and poverty}

Poverty and overpopulation are believed to be the main causes of forest loss according to the international agencies such as FAO and intergovernmental bodies. Rapid population growth is a major indirect and over-arching cause of deforestation. More people require more food and space which requires more land for agriculture and habitation. This in turn results in more clearing of forests. Arguably increasing population is the biggest challenge of all to achieve sustainable management of human life support systems and controlling population growth is perhaps the best single thing that can be done to promote sustainability (Colchester and Lohmann, 1993).

\section{Method And Material}

\subsection{The study area}

The study has been conducted in Shabe Sombo woreda located in Jimma Zone, Oromia regional state. The zone is one of the areas with remaining natural forests in the country. Shabe sombo is found at 50 $\mathrm{km}$ far from Jimma and Jimma is located $356 \mathrm{~km}$ far from Addis Ababa Ethiopia.

\subsection{Study Design}

A cross sectional study design was conducted to investigate factors contributing to deforestation in Shabe sombo woreda.

\subsection{Population}




\subsubsection{Source population}

The source of population Were all households found in Shabesombo Woreda, Jimma Zone, Oromia.

\subsubsection{Study population}

The study population of this study was all householders participated in this investigation by giving data or important information about the title of this paper.

\subsection{Sample Size \& Sampling Technique}

The sample size of this study was calculated and accepted from the total households of (1200 households) by using the following formula

$$
\begin{aligned}
& \mathrm{n}=\underline{\mathrm{Z}^{2} \mathrm{pqN}} \quad \text { (Daniel 1995) } \\
& \mathrm{d}^{2}(\mathrm{~N}-1)+\mathrm{Z}^{2} \mathrm{pq} \quad \text { Where } \mathrm{n}=\text { Sample size } \mathrm{q}=1-\mathrm{p}=1-0.5=0.5 \\
& \mathrm{~N}=\text { Total number of population } \\
& \mathrm{Z}=\text { Level of confidence with } 95 \% \approx 1.96 \\
& \mathrm{~d}=\text { Margin of error } \\
& \mathrm{P}=\text { proportion of population (50\%) for maximum sample size } \\
& \mathrm{n}=\text { Sample size }=100
\end{aligned}
$$

By using the above formula the sample size of 1200 house holders was calculated and finally 100 house holders were selected as a sample size using simple random sampling method.

\subsection{Data Collection instrument}

Data were collected by using open and close ended questionnaires for gathering important information used for this study.

\subsection{Method of Data Analysis}

After collected data cleared and checked for their completeness, data have been then analyzed using a scientific calculator and results were presented in the form of table and paragraphs. 


\subsection{Ethical issue}

The researcher was asked request letter from Jimma University, Biology head department office and Biology head department was gave request letter to the researcher. Having the letter from Jimma University the researcher was asked request manager of to get the data of House holders found in that Woreda and the woreda's manager has been given the right number of house holders.

\section{Result}

This chapter deals with presentation of data analysis and discussion on the collected data. The data collected form respondents through questionnaire are presented in the form of tables. Even though the researcher planned to get response from 100 householders but because of some peoples were not interested to give their response/they were unwilling to give their idea, the data were collected from 96 householders only.

Table 1 Socio-demographic characteristics of respondents 


\begin{tabular}{|c|c|c|c|}
\hline \multirow[t]{2}{*}{ No } & \multirow[t]{2}{*}{ Item } & \multicolumn{2}{|r|}{ Response } \\
\hline & & Number & Percentage \\
\hline \multirow[t]{6}{*}{1} & a) Age:- & & \\
\hline & $15-35$ & 31 & 32.29 \\
\hline & $36-50$ & 47 & 49.96 \\
\hline & $51-65$ & 12 & 12.5 \\
\hline & $>65$ & 6 & 6.25 \\
\hline & Total & 96 & 100 \\
\hline \multirow[t]{4}{*}{2} & b) Sex:- & & \\
\hline & Male & 78 & 79.167 \\
\hline & Female & 18 & 20.833 \\
\hline & Total & 96 & 100 \\
\hline \multirow[t]{6}{*}{3} & c) Education status:- & & \\
\hline & Elementary & 73 & 76 \\
\hline & Secondary & 23 & 24 \\
\hline & College diploma & - & - \\
\hline & Degree and above & - & - \\
\hline & Total & 96 & 100 \\
\hline
\end{tabular}

The table shows demographic characteristics of respondents which contains age, sex and educations status of the respondents. Majority of the respondents participated to give data for this investigation were males $78(79 \%)$ and $18(21 \%)$ females. Whereas most of them are found between the age interval from $36-50$ years $47(49.96 \%)$ of them and $31(32.3 \%)$ of the respondents were between the age group from 15-35 years old. While the minority of the respondents were found between the age group of were $\geq 51$ years old. Regarding to the educational status of the respondents, $73(76 \%)$ of them were elementary completed and $23(24 \%)$ of the respondents were secondary education completed (Table 1 ).

Table 2 Major factors that contribute for deforestation in the study area 
Item

Response

Number

Percentage

a) Fire wood and destroying the forest to prevent human enemy

12

12.5

animals such as Tiger

b) Agricultural expansion and destroying forest to prevent crop enemy animals such as monkey

a) Road construction

c) cutting trees for traditional medicinal use

30

31.3

a) Road construction

d) investor activities

7

7.3

e) the number of population increased

3

3.2

9

9.4

f) new settlers from other areas

27

28.2

Total

8

8.3

96

$100 \%$

In the current study, agricultural expansion was the major factor that resulted in deforestation. About $30(31.3 \%)$, followed by the number of population increased $27(28.2 \%)$ whereas $12(12.5 \%)$ of the respondents said road fire wood and destroying the forest to prevent human enemy animals such as Tiger was also the minor factor contributes to deforestation in the study area. Investors activities new settlers from other area and cutting trees for traditional medicine were the least factors contributing deforestation in the study area (Table 2).

Table 3 the need of land for coffee plantation is one of the most factors that contribute deforestation.

\begin{tabular}{|c|c|c|c|}
\hline \multirow{2}{*}{\multicolumn{2}{|c|}{ Item }} & \multicolumn{2}{|r|}{ Response } \\
\hline & & Number & Percentage \\
\hline & agree & 45 & 46.9 \\
\hline b) & strongly agree & 25 & 26 \\
\hline & disagree & 20 & 20.83 \\
\hline & strongly disagree & 6 & 6.25 \\
\hline Tot & & 96 & $100 \%$ \\
\hline
\end{tabular}

Majority of the respondents $45(46.9 \%)$ were agreed as people were practicing deforestation for the need land for coffee plantation. About $25(26 \%)$ of the respondents strongly agreed on the need land for coffee 
plantation was one of the most factor contributing to deforestation. Generally, around $72.9 \%$ of the respondents agreed and strongly agreed that, the need of land for coffee plantation was the factor that contributes to deforestation (Table 3).

Table 4 the one which is frequently practiced in the study area is

\begin{tabular}{|c|c|c|c|}
\hline \multirow[b]{2}{*}{ Item } & & \multicolumn{2}{|r|}{ Response } \\
\hline & & Number & Percentage \\
\hline a) & Cutting trees for preparation of charcoal & 60 & 62.5 \\
\hline b) & For timber & & \\
\hline \multirow[t]{2}{*}{ c) } & Using trees for construction purpose & 20 & 20.83 \\
\hline & & 16 & 16.667 \\
\hline \multicolumn{2}{|c|}{ Total } & 96 & $100 \%$ \\
\hline
\end{tabular}

Majority of the respondents $60(62.5 \%)$ said that cutting trees for preparation of charcoal was the factor which was frequently practiced in the study area followed by $20(20.8 \%)$ of the respondents reported as the need trees for timber production was the factor. While the need of trees for construction purpose was the minor factor contributing to deforestation (Table 4).

Table 5 information on the impact of deforestation and people's perception on the current status of forest in Shabe Sombo. 
Response

1) Information on the impact of

Deforestation on economy, environmental, soil and biodiversity.

Number Percentage

$\begin{array}{lll}\text { a) Has impact } & 55 & 54.2\end{array}$

b) Has no impact

$41 \quad 45.83$

Total

$96 \quad 100 \%$

2) People's perception on the current status of forest in Shabe Sombo Number Percentage
a) Decreasing
44
45.8
b) Increasing
52
54.2
Total
96
$100 \%$

About 55(54.2\%) of the respondents know that deforestation has impact on economy, environmental, soil and biodiversity. Whereas $41(45.8 \%)$ of the respondents did not know as deforestation has impact. Majority of the respondents $52(54 \%)$ said that the current forest status of the study area is increasing this is due to the knowledge of majority of the respondents toward the impact of deforestation followed by minority of the respondents $44(45.8 \%)$ reported that the current forest status of the study area is decreasing (Table 5).

\section{Discussion And Conclusion}

\subsection{Discussion}

According to Table 2 most of the respondents, 30(31.3\%) said that deforestation was practiced for agricultural purpose in Shabe Sombo. About $12(12.5 \%)$ of the respondents answered as fire wood is one of the factor that was contributing to deforestation in Shabe Somo. This is online agreement with the work of Ross (1996) Shifting agriculture also called slash and burn agriculture is the clearing of forested land for raising or growing the crops until the soil is exhausted of nutrients and/or the site is overtaken by weeds and then moving on to clear more forest. It is been often reported as the main agent of deforestation. Smallholder production in deforestation and the growing number of such producers notably shifting cultivators were the main cause of deforestation. Mostly all reports indicate shifting agriculture as responsible for about one half of tropical deforestation and some put it up to two-thirds. Shifting agriculture was greatest in Asia (about $30 \%$ ) but only about 15 per cent over the whole tropical 
world. It appears that the proportion of direct conversion of forest to agriculture is increasing and the proportion of shifting agriculture is decreasing with time.

According to table 3 most of the respondents agreed or $45(46.875 \%) \& 2.5(26 \%)$ strongly agreed as the (need landed for Coffee plantation is one of the most factors that contribute to deforestation. This is similar with the study of Gatzweileret al., (2007) Despite the downward trend in world coffee prices, farmers are unable to receive government assistance for anything but the cultivation of coffee. Yet, an average coffee plantation remains productive for a mere 20 years, after which time the land may be planted with grass and made into pasture for livestock, but eventually must be abandoned. This process is costly, coffee markets are unstable, and the forest continues to be cleared.

As it was shown in table 4 about 60 (62.5\%) of the respondents gave their opinion as cutting frees for charcoal is one of the most factor contributing to deforestation \& around $20 / 20.83 \%$ ) of respondent also said timber is also one focus that is contributing to deforestation. This is on line agreement with the study conducted by FAO, (2002) the causes of deforestation are varied but may broadly be categorized into anthropogenic and natural factors. For the anthropogenic factors, increased wood fuel collection, clearing of forests for agriculture, illegal and poorly regulated timber extraction, social and environmental conflicts, increasing urbanization and industrialization are the primary known causes for the loss of forests and woodlands.

As it was mentioned in table 2 about 30 (31.3\%) of respondents said that peoples are destroying forest to prevent crop enemy animals such as monkey. From table 5, mentioned under the result of this paper $55(54.167 \%)$ of them have enough knowledge about the effect of deforest. This shows that peoples have somewhat awareness about the impact happened by deforestation. This is supported by the study conducted by Regassa (2001) Local communities, therefore, are the primary stewards of forest resources. These resources are usually characterized by the local communities' culture and management systems, where cultures are materially and spiritually built upon the physical world of the forests. Local communities' proper access to forest resources around them and respect to their traditional institutions and systems of management of these resources provides the opportunity for safeguarding the resources sustainably.

Even though the local communities have awareness about the effect of deforestation some peoples of Shabe Somo are practicing deforestation until this time. According to table 2 presented under the result part of this paper the main factor or cause of this deforestation in this Kebele is the increment of human population. About $27(28.2 \%)$ of the people living in Shabe Somo said that people are practicing deforestation for the purpose of expanding land for agriculture. This is very similar with the work of Spracklen (2012) individual farmers do not have many other options than converting forests into agricultural land if they are exposed to severe food insecurity. Their time preference rates are low which means they prefer food today over tomorrow and they definitely cannot carry the costs of forest conservation for the larger national or global society. 


\subsection{Conclusion}

According to the data gathered and analyzed, the most contributing factors to deforestation is expanding agricultural farm land. Because of population growth and the need for food increased people interested to expand farm land which is the base line for enough food availability. As well as cutting trees for charcoal is also another factor contributing to deforestation in Shabe Somo. Because of peoples used charcoal for cooking food and they use as an income/ they sell and get money. To have this important charcoal, they are going to cut trees and change it to charcoal by burning. However there are different factors contributing to deforestation, the current deforestation status of Shabe Somo is not decreasing. Because people have full awareness of the impact of deforestation, they use in sustainable way or when they use some trees for different purposes the replace the same trees as much as possible

\section{Recommendations}

From the collected and analyzed data the investigator has tried to mention the following recommendation for concerned bodies.

$\nabla$ Since the most factors contributing to deforestation is Expanding farm land for agriculture, the community those are practicing this deforestation should have to have enough knowledge about the impact of deforestation on both living thing and environmental change.

$\nabla$ There should be controlling and giving immediate solution for peoples those are practicing deforestation for the case of charcoal.

Q Farmers those are practicing deforestation for the case of need land for coffee plantation also should be followed by concerned bodies to decrease deforestation practice in Shabe Sombo.

\section{References}

Anonymous. 2005. Ecosystems and Human well-being: synthesis. Millennium ecosystem Assessment.Island Press, Washington D C.

Anonymous, 2010. Global Forest Resources Assessment, 2010-Main Report. FAO Forestry Paper 163. Rome, Italy. 340p.

Barraclough, S. and Ghimire, K. B. 2000.Agricultural Expansion and Tropical Deforestation.

Earthscan.

Betts, R. A. (2004). . The role of ecosystem-atmosphere interactions in simulated Amazonian precipitation decrease and forest dieback under global climate warming 
Carvalho, G.; Moutinho, P.; Nepstad, D.; Mattos, L. and Santilli, M. 2004. An Amazon perspective on the forest-climate connection: opportunity for climate mitigation, conservation and development?

Environment, Development and Sustainability 6: 163-174.

Colchester, M. And Lohmann, L. 1993. The Struggle for land and the fate of forest. Zed books,London.

Food and Agriculture Organization (2002) Global Forest Resources Assessment- Main Report, FAO Forestry Paper.

Food and Agriculture Organization (2010), "Criteria and Indicators for Sustainable wood fuels", Rome, Italy, pp. 5.

Gatzweiler, F. Reichenhuber, A and Hein, L. 2007. Why Financial Incentives can Destroy Economically Valuable Biodiversity in Ethiopia.

Hays, J. 2008.Deforestation and desertification in China. http://factsanddetails.com/china.

Insaidoo, T. F.G., Ros-Tonen, M. A.F., Hoogenbosch, L. and Acheampong, E. (2012) Addressing Forest Degradation and Timber Deficits in Ghana, ETFRN News 53.

Mather, A. S. 1991. Global Forest Resources.International Book Distributors, Dehra Dun.

Parry, J (2003). "Tree choppers become tree planters," Appropriate Technology, 30(4), 38-39

Raloff, J. 1989. Where Acids Reign. Science News July 22. Pp 56-58.

Repetto, R. 1990. Deforestation in the Tropics. Scientific American April, p. 37.

Rowe, R.; Sharma, N. P. and Bowder, J. 1992. Deforestation: problems, causes and concern.

In: Managing the world's forest: looking for balance between conservation and development, ed. Sharma, N. P. Pp 33-46.

Ross, 1996.Conditionality and logging reform in the tropics. In: Institutions for Environmental

Aid: Problems and Prospects, eds. Keohane, R. O. and Leve, M A. Pp 167-197.

Sands, R. 2005.Forestry in a Global Context.CABI Publishing.

Spracklen, D. V., Arnold, S. R. \& Taylor, C. M. (2012) Observations of increased tropical rainfall preceded by air passage over forests. Nature 489, 282-283. 